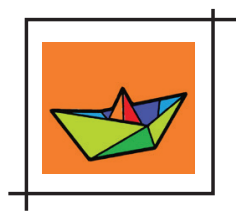

\title{
EDUCAÇÃO ESCOLAR INDÍGENA EM ESCOLA NÃO INDÍGENA: COMPARTILHANDO SABERES EM UMA PRÁTICA DE ENSINO DE CIÊNCIAS DA NATUREZA
}

\author{
Maria Rosemi Araujo Nascimento* \\ Marina Graziela Feldmann**
}

Resumo: Este artigo tem como objetivo socializar uma prática em aulas de Ciências da Natureza ministradas a alunos indígenas em escola não indígena. Trata-se de um recorte da pesquisa de campo da tese de doutorado Formação de professores e currículo: uma prática em Ciências da Natureza para a diversidade com alunos indígenas em escola não indigena na cidade de Manaus/AM (NASCIMENTO, 2019), na qual se vivenciou a experiência de uma aula compartilhada entre uma professora pedagoga regente de uma turma de primeiro ano, um cacique mura e uma professora indígena de Cultura Indígena e de Língua Nheengatu. A aula compartilhada foi a principal técnica utilizada para coleta de dados, cuja finalidade foi trabalhar uma didática na perspectiva de uma interculturalidade. Ao final, os sujeitos colaboradores da pesquisa apresentaram diversas contribuições que nos permitiram estabelecer um parâmetro acerca da importância do compartilhamento de saberes. Nosso propósito ao possibilitar tal compartilhamento foi uma tentativa de visibilizar a cultura indigena entre outras culturas presentes na escola que permanecem despercebidas. Esse raciocínio nos permitiu realizar um debate crítico em torno do assunto discutido neste trabalho, uma vez que se trata de uma abordagem para a valorização da diversidade cultural dentro de um contexto multicultural.

Palavras-chave: Educação escolar indigena. Alunos indigenas. Escola não indigena. Ensino de Ciências Naturais. Aula compartilhada.

\section{INTRODUÇÃO}

Este texto faz parte da tese de doutorado Formação de professores e currículo: uma prática em Ciências da Natureza para a diversidade com alunos indigenas em escola não indígena

\footnotetext{
* Doutora em Educação pela Pontifícia Universidade Católica de São Paulo (PUC-SP). Mestre em Educação em Ciências na Amazônia pela Universidade do Estado do Amazonas (UEA). Pedagoga pela Universidade Federal do Amazonas (Ufam) e professora da Rede Pública Municipal de Manaus.

** Doutora e mestre em Educação pela Pontifícia Universidade Católica de São Paulo (PUC-SP). Graduada em Pedagogia pela PUC-SP. Docente e pesquisadora do Programa de Pós-Graduação em Educação da PUC-SP.
} 
na cidade de Manaus/AM (NASCIMENTO, 2019) e apresentamos como objetivo socializar a experiência vivenciada durante a pesquisa, na qual se pôde experimentar um momento de compartilhamento na perspectiva de uma educação intercultural.

Para tanto, evidenciaremos uma prática didática com o componente curricular Ciências da Natureza para alunos indígenas inseridos em escola não indígena, por meio de uma aula compartilhada entre sujeitos pertencentes a um mesmo contexto - aquele em que a escola está inserida -, porém com origens e visões diferentes.

Para compreendermos melhor a proposta da técnica da aula compartilhada utilizada na pesquisa, apresentaremos o desenvolvimento dela e o modo como se organizou o processo para coleta de dados durante a pesquisa de campo.

Abordaremos como se deu a participação de cada sujeito colaborador da aula compartiIhada, a qual se constitui em uma proposta em que esses sujeitos são corresponsáveis por ministrar o conteúdo. Apresentaremos também a maneira como cada um participou, contribuindo para uma visão ampliada do ensino de Ciências da Natureza, uma vez que eles puderam mostrar seu modo de ver o mundo para a sala de aula em uma experiência colaborativa ímpar. Como tópico complementar da experiência vivenciada pelos sujeitos, traremos a visão deles acerca da contribuição da pesquisa para as suas vidas, enquanto indivíduos educadores da área de Ciências da Natureza.

\section{Metodologia}

0 presente artigo, cujo título é Educação escolar indigena em escola não indígena: compartilhando saberes em uma prática de ensino de Ciências da Natureza, nos possibilitou uma metodologia baseada na pesquisa qualitativa, na qual apresentamos resultados de uma pesquisa de campo, realizada no contexto de uma escola na zona rural, da rede municipal de Manaus - AM, onde se encontra uma realidade com uma diversidade cultural relacionada às questões étnicas e geográficas.

Durante o processo de investigação descobrimos, no contexto da escola, diversos sujeitos, com diversos lugares de fala, implicados no processo de construção do conhecimento dos alunos indígenas inseridos na escola não indigena, sendo eles: a professora regente da turma do primeiro ano do ensino fundamental; um cacique mura, chefe da comunidade da qual os alunos indígenas faziam parte e uma professora indígena da etnia mura, também pertencente à mesma comunidade indígena, que trabalhava com o ensino da Língua Nheengatu. Esses sujeitos impactavam a vida daqueles alunos em processo de desenvolvimento identitário, enquanto educandos oriundos de uma cultura invisibilizada pela cultural local dominante. Esses indicativos foram fundamentais para a escolha dos protagonistas colaboradores da aula compartilhada, que foi a principal técnica para coleta de dados utilizada em nossa pesquisa. Consideramos de maior relevância a participação colaborativa desses sujeitos para a 
construção do diálogo ora apresentado neste artigo, para a validação do nosso estudo em torno da educação escolar indígena. Além da aula compartilhada, utilizamos também a observação sistemática da prática da professora em sala de aula e um questionário misto, cujo objetivo foi levantar dados preliminares relevantes para a pesquisa.

\section{SABERES COMPARTILHADOS EM CIÊNCIAS DA NATUREZA}

Iniciamos esta reflexão esclarecendo um pouco sobre a aprendizagem colaborativa. Tal aprendizagem constitui-se atualmente em uma oportunidade de compartilhar saberes, resolver problemas, protagonizar aprendizagens, permitindo ao aluno criar suas hipóteses para aprender e pensar criticamente.

Do ponto de vista da prática pedagógica, podemos aproveitar o conceito para agregar valor à formação e ao ensino, pois também os professores podem aprender a trabalhar colaborativamente, por meio de ações nas quais todos são responsáveis pelo ensino-aprendizagem, podendo inclusive compartilhar com o colega de trabalho, além das vivências, experiências e saberes, na própria sala de aula. Nesse sentido, Tânia Graça $(2016$, p. 25) afirma que "o aprender 'em conjunto' pode ser interpretado de diversas maneiras, como situações de aprendizagem presenciais ou virtuais. Assim sendo, esta prática pode assumir múltiplas facetas, podendo haver dinâmicas e resultados de aprendizagem diferentes para cada contexto específico".

Nessa mesma linha de pensamento, Torres e Irala $(2014$, p. 65), asseguram que

\footnotetext{
Em uma visão ampla do que significa aprender colaborativamente [...] espera-se que ocorra a aprendizagem como efeito colateral de uma interação entre pares que trabalham em sistema de interdependência na resolução de problemas ou na realização de uma tarefa; [...] a interação em grupos realça a aprendizagem mais do que em um esforço individual; [...] e a aprendizagem mais eficiente, assim como um trabalho mais eficiente, é colaborativa e social em vez de competitiva e isolada.
}

Desse modo, obteremos melhor aproveitamento dos recursos, dos saberes e, consequentemente, maiores possibilidades de uma aprendizagem significativa. Entretanto, nossa pretensão aqui não é de aprofundamento do estudo da aprendizagem colaborativa, porém queremos destacar o potencial colaborativo presente na aula compartilhada de modo que, ao trabalharmos com essa técnica, mostramos quanto o engajamento de todos os envolvidos em prol do processo ensino-aprendizagem com foco no aluno se constitui em uma parceria promissora para o alcance dos objetivos educativos, especialmente como uma ferramenta para uma proposta de educação multi ou intercultural.

Nesse sentido, a aula compartilhada, embora se trate de uma ação modelar que, se realizada entre os pares da escola, sejam eles professor-professor, aluno-aluno ou ainda outros 
sujeitos com formações similares, possui impacto positivo, impactará muito mais se trabaIhada entre a diversidade de saberes. Nosso propósito com essa ação foi possibilitar de maneira prática uma oportunidade que representasse uma novidade naquele contexto de escola, pois embora o nosso foco tenham sido alunos indigenas em escola não indígena, a realidade que se apresentou diante de nós foi um cenário cheio de nuances culturais, no qual pudemos observar alunos oriundos da Venezuela, Colômbia, Haiti, índios e não índios dentro de um mesmo espaço escolar. E apesar dessa diversidade cultural, não observamos que questões dessa natureza tenham sido exploradas ou trabalhadas naquele contexto, uma vez que a diversidade da língua, dos costumes e hábitos, valores, entre outros influenciam diretamente o desenvolvimento e sucesso das aulas ministradas na escola.

A invisibilidade de determinadas culturas foi algo que nos chamou a atenção, por exemplo, quando o aluno oriundo da Colômbia não conseguiu realizar as tarefas por não compreender a língua portuguesa, assim como quando o aluno indígena não conseguiu ficar sentado na cadeira por várias horas, em razão de que no costume indígena as crianças são livres para aprender experimentando. Tal invisibilidade pode caracterizar que nas nossas escolas a cultura de quem chega é subjugada à cultura dominante e dessa maneira não se oportuniza a troca entre as culturas e não se permite, aos que chegam, expressar seus valores, crenças e visão de mundo e, nesse caso específico, o mundo escolar.

Então, como avançar no trabalho com a diversidade cultural na escola e com a interculturalidade? Todos precisam estar engajados nessa empreitada que desafia a escola contemporânea, uma vez que tal situação não é responsabilidade única e tampouco é culpa da escola, pois, segundo Mylene Santiago (2013, p. 9), "a interculturalidade no contexto brasileiro é fortemente influenciada pela transição democrática dos anos de 1980, que marcam o início da visibilidade e do aumento da legitimidade da diversidade cultural no espaço público". Com isso, iniciamos um esforço para compreender e empreender interações que possibilitem a prática da interculturalidade na escola enquanto espaço público de aprendizagem, valorização e promoção de culturas.

Durante a trajetória da pesquisa, em conversa com os segmentos da escola, propusemos a implementação de uma aula compartilhada e socialização dos saberes, com ênfase no componente curricular Ciências da Natureza. Contudo, para a realização da aula compartiIhada, foi necessário não só um diálogo, mas também um planejamento dialógico, no qual as partes envolvidas no processo educativo colocaram suas concepções acerca do papel da escola e da cultura no âmbito do desenvolvimento cognitivo, visto que, em um momento como esse, deve-se respeitar a contribuição que cada segmento traz para o processo de ensino-aprendizagem.

Nossos sujeitos colaboradores, para a realização da aula compartilhada, foram a professora regente da turma do primeiro ano, a professora indígena de Cultura e Língua Nheengatu no Espaço Cultural da comunidade indigena Nações Indígenas e o cacique mura, chefe da 
comunidade. Vale ressaltar que a referida aula foi ministrada para alunos indígenas e não indigenas que compunham a turma do primeiro ano do ensino fundamental. Assim sendo, a atividade desenvolvida permitiu conhecermos as possibilidades e os desafios do ensino de Ciências da Natureza ao utilizarmos uma proposta envolvendo uma postura com traços de uma didática para a interculturalidade. Nesse contexto, Santiago, Akkari e Marques (2013, p. 9) inferem que "a inserção das culturas afro-brasileira e indigena no currículo escolar demonstram que a interculturalidade prospera e que sociedades se tornam pluralistas e democráticas", ao favorecerem a troca de saberes entre as diversas culturas sem hierarquizá-las.

Observamos que o primeiro impacto para a escola foi que no dia marcado para a reunião de planejamento da aula a ser compartilhada, o cacique apresentou-se a caráter, usando cocar e colar próprios dessa liderança indígena. Os olhares se voltaram para ele, como se jamais imaginassem aquela cena, em que um indígena, não professor, entraria na escola para participar do planejamento de uma aula a ser ministrada de modo colaborativo. Paradoxalmente, a mesma escola que recebe alunos indígenas não se prepara para receber os pais indígenas, com seus costumes? Como não imaginar, se os pais indigenas estão presentes nas reuniões e eventos? Como não imaginar, se o indígena está presente na região? Precisamos tornar visivel a diversidade cultural existente na escola, pois presente ela já se encontra, faz parte do cotidiano e interfere nos processos e resultados das aprendizagens.

Figura 1 Reunião para planejamento da aula compartilhada

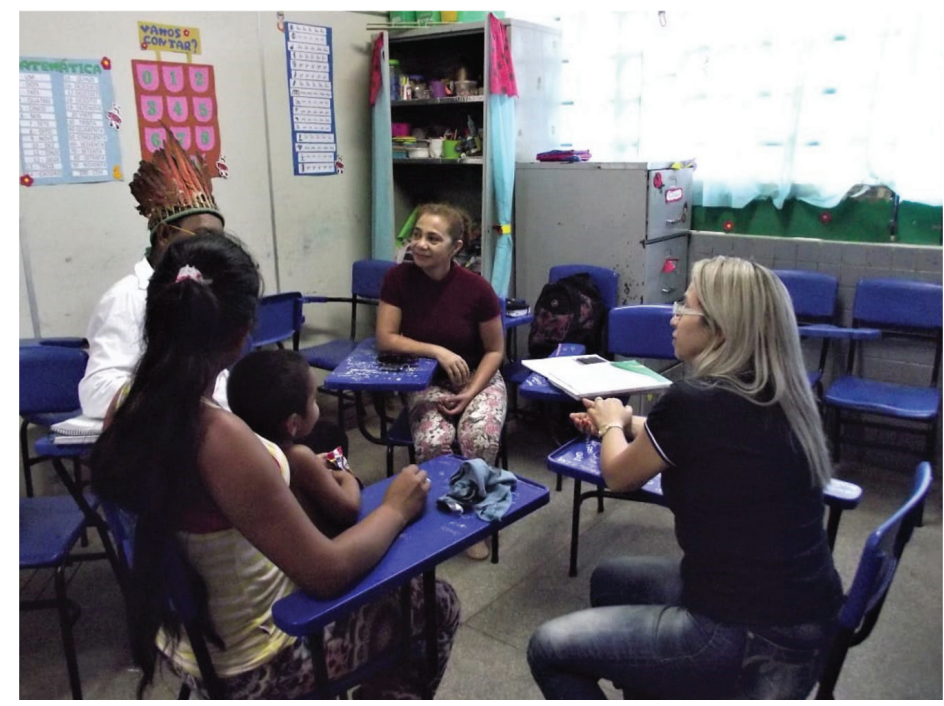

Nota: presentes a pesquisadora, a professora da turma do primeiro ano, a professora de Língua Nheengatu e o cacique mura, chefe da comunidade indigena Nações Indígenas.

Fonte: Nascimento, 2019. - Foto: Fernanda Holanda. 
A Figura 1 apresenta uma realidade que poderia ser mais frequente nas escolas, não somente a questão da presença participativa do indígena, como também a presença de outras culturas de todos os cantos do país. Há ainda uma particularidade da professora indígena, que leva consigo o filho, um hábito próprio da cultura indígena, em que as crianças participam das atividades dos adultos, porém como uma brincadeira e, assim, aprendem regras que servirão para sua sobrevivência quando crescerem. Especificamente nesse caso, a professora justificou sua atitude afirmando que não tinha com quem deixar o filho, o que revela mais uma questão de política pública a ser discutida, a construção de creches. Embora esse seja um assunto pertinente e relevante, não é nossa intenção abordar essa discussão, uma vez que não tem relação direta com nosso objeto de estudo.

0 encontro em evidência, em que definimos o conteúdo a ser trabalhado, as estratégias a serem utilizadas e a colaboração de cada um dos participantes dessa experiência pedagógica e educativa, teve a finalidade de planejarmos a aula. Vale ressaltar que esse momento de compartilhamento trouxe significados que antes não haviam sido observados, como, por exemplo, a influência do cacique sobre as famílias da comunidade indígena e a importância dos saberes vividos pelos indigenas mais velhos para a manutenção da cultura de cada povo. Essa iniciativa nos trouxe a compreensão de que promover a visibilidade do indígena, por meio da participação e colaboração no processo de ensino da escola, pode constituir-se em um caminho para a promoção da interculturalidade, além de ter possibilitado um encontro entre saberes que se desenvolviam separadamente, mas que ao serem integrados nos permitiram um melhor conhecimento do todo que envolve a questão dos alunos indígenas inseridos em escola não indígena e a prática com o componente curricular Ciências da Natureza, pois, na oportunidade, cada segmento pôde apresentar uma face do conhecimento relevante para o desenvolvimento cognitivo, social e cultural dos alunos.

Na ocasião em que se deu a aula compartilhada, ao apresentar os animais regionais para os alunos, a professora regente da turma trouxe para o grupo o conhecimento do conteúdo formal prescrito, historicamente acumulado e aprendido durante a sua formação inicial. Ela destacou os nomes dos animais, a classificação, o tipo de alimentação e o lugar onde moram na natureza. 0 recurso utilizado pela professora foi pequenos cartazes, os quais ela afixou no quadro branco, e os animais escolhidos foram paca, veado, porco-do-mato, onça-pintada, capivara e jabuti, animais que fazem parte da fauna amazonense, contemplados no conteúdo diversidade de seres vivos, no eixo Ambiente e Vida, da proposta do Bloco Pedagógico. No decorrer da exposição, a professora fez perguntas às crianças, que interagiram com entusiasmo respondendo às questões formuladas pela professora, apresentadas de forma simples e direta, conforme observamos no diálogo abaixo: 
Professora - A onça é um mamífero carnivoro que mora nas florestas.

Onde a onça mora?

Alunos - Na floresta!

Professora - O que ela come?

Alunos - Carne!

Aluno - Egente também! (NASCIMENTO, 2019, p. 161).

Enquanto a professora explicava para as crianças, essas se interessavam em apreciar as imagens e o colorido contido nelas. Os cartazes foram explorados pelas crianças, que se aproximaram do quadro para visualizar melhor as imagens. A professora concluiu explicando que devemos cuidar dos animais e da natureza para garantirmos nossa existência. Ao encerrar o momento da aula expositivo-participativa, seguiu-se com participação do cacique, que, em uma conversa muito tranquila, dialogou sobre o mito da onça e seus hábitos, sobre como ela vive na floresta e o que ocorre quando destruímos a floresta. Falou lamentando:

\begin{abstract}
A yawareté (onça) só sai da floresta pra ir em busca de alimento; ela não é má, ela quer sobreviver e quando tiram os outros animais da floresta que servem de alimento para ela, ela sai para caçar outros alimentos; o indio mora na floresta e ele cuida da floresta, para que todos os seres vivos possam sobreviver na floresta, no rio e na terra (NASCIMENTO, 2019, p. 161).
\end{abstract}

Durante o diálogo, os alunos se mantiveram atentos e identificaram-se por meio de falas como: "A onça é bem grande!"; "A onça não é má!". Eles pareceram tranquilos durante a atividade. Nesse contexto, o que observamos presente na fala do cacique é toda a força de uma cultura para a sustentabilidade, pois o indígena sabe que é preciso manter a floresta viva, para que ele próprio, que também é parte da natureza, mantenha sua existência, cultura, mitos, pois compreende que ele faz parte do equilibrio do ciclo da vida na natureza.

0 indigena entende que existe um tempo para tudo na natureza: o tempo da floresta; o tempo do rio; o tempo da Terra, que se renova de forma cíclica para manter a sustentabilidade ecológica. Maria Nascimento (2010, p. 90) afirma que, para esses povos,

Os saberes tradicionais atravessam os séculos, gerando a sustentabilidade histórica; a força da narrativa do mito traz o tempo de origem da primeira aparição do mesmo, para a sustentabilidade religiosa; a ciência sustentável desenvolvida pelo Índio respeita o tempo do rio (seca ou cheia), o tempo da chuva, o tempo do solo e o tempo da floresta, para sustentabilidade territorial; o conhecimento construido pelo indigena se renova de tempo em tempo e se adapta a cada geração, fomentando a sustentabilidade existencial; os saberes indigenas se cruzam com os conhecimentos ocidentais, sem perder a sua essência de ori- 
gem, dando lugar a um modo alternativo de pensar a construção de conceitos científicos, favorecendo, enfim, a relação entre a triade interculturalidade, territorialidade e sustentabilidade.

Foi interessante perceber que os alunos das outras turmas foram à sala do primeiro ano para ver o que estava acontecendo e que alguns, por serem da comunidade indígena do cacique, passavam para cumprimentá-lo, acenando com a mão e com um sorriso no rosto. Os demais professores da escola observaram o movimento e uma das professoras de Educação Física aproximou-se e parabenizou-nos, elogiando a nossa iniciativa de promover uma atividade envolvendo a cultura indigena.

A gestora esteve presente em um determinado momento da atividade e posicionou-se no sentido de apoiar-nos em qualquer situação que precisássemos. Outra situação que ocorreu foi a presença da equipe de comunicação da Secretaria Municipal de Educação (Semed) de Manaus, que registrou a atividade com fotos e entrevistou alguns alunos e o cacique mura. A matéria foi publicada no portal da Semed, para que toda a comunidade escolar tivesse acesso. Entretanto, não obtivemos nenhum feedback da Secretaria acerca do evento.

Figura 20 cacique mura contando as histórias dos animais mamiferos da fauna regional amazonense para a turma do primeiro ano

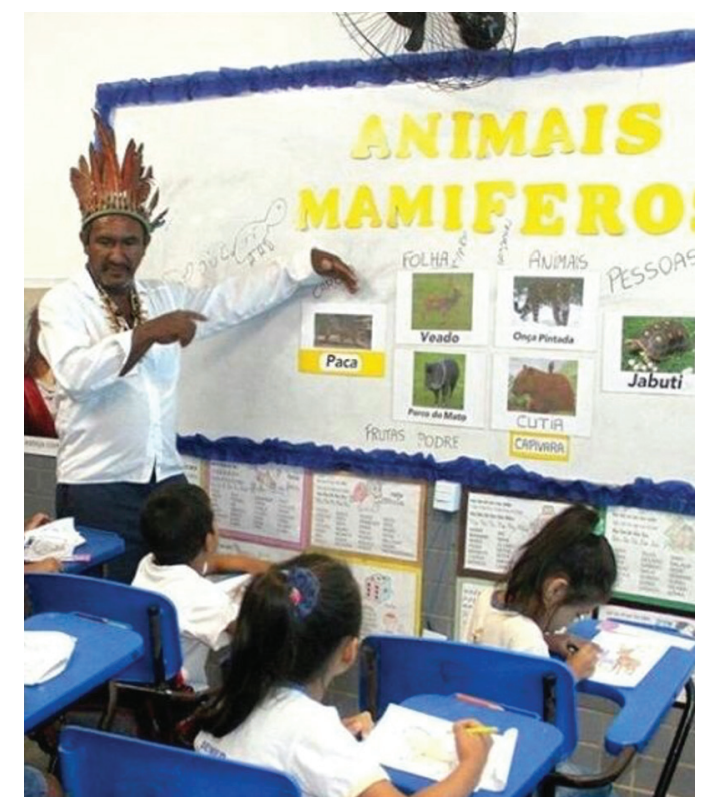

Fonte: Marinho (2017). 
Após o momento compartilhado com o cacique, a professora de Língua Nheengatu apresentou às crianças dois jogos interativos, com os quais essas iriam fixar os nomes dos animais mamiferos regionais apresentados pela professora e pelo cacique. Um dos jogos foi um dado contendo a imagem e o nome dos animais escritos na língua nheengatu. Ao jogar o dado, de acordo com o nome que estivesse em evidência, os alunos teriam que montar um quebra-cabeça até formar o nome do animal em língua portuguesa ou nheengatu.

Tabela 1 Lista de animais regionais trabalhados na aula compartilhada

\begin{tabular}{ll}
\multicolumn{1}{c}{ Português } & \multicolumn{1}{c}{ Nheengatu } \\
\hline Capivara & Capiwara \\
\hline Jabuti & Akutí \\
\hline Paca & Yavatí \\
\hline Porco-do-mato & Tayasú \\
\hline Onça-pintada & Yawareté \\
\hline Veado & Çuaçú \\
\hline
\end{tabular}

Fonte: Nascimento, 2019, p. 163.

A atividade realizada pela professora indígena proporcionou um momento de descontração no qual as crianças puderam expressar o seu aprendizado, porém, sem perceber que dessa forma poderiam estar sendo avaliadas, o que torna o uso do lúdico uma ferramenta totalmente acertada na interação entre as crianças e entre o adulto e as crianças.

0 trabalho desenvolvido pela professora de Cultura Indigena e Língua Nheengatu foi uma amostra das atividades que ela realiza com os alunos indígenas da escola que moram na comunidade da qual ela também faz parte. Quando as crianças a viram entrando na escola, receberam-na com carinho, expressando sua alegria por meio de abraços individuais e coletivos, deixando clara a relação afetiva entre eles e a professora indigena da etnia mura. Por sua vez, a professora indígena sentiu-se valorizada por demonstrar um pouco do trabalho que realiza na comunidade Nações Indígenas e afirmou que "eu gosto muito do trabalho com os jogos, porque a criança se diverte e ao mesmo tempo aprende a respeitar a natureza" (NASCIMENTO, 2019, p. 164). 
Figura 3 Preparativos antes da aula compartilhada, com o tema animais mamíferos regionais da fauna amazonense, na turma do primeiro ano

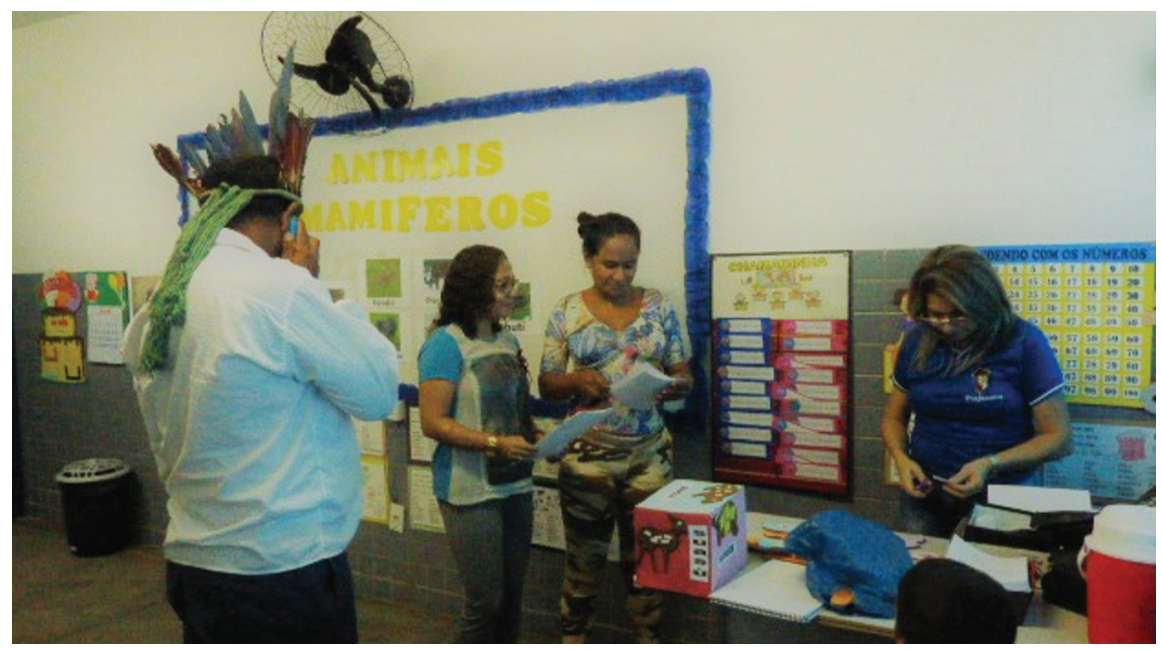

Nota: quando discutíamos sobre a participação de cada um, o cacique recebeu uma ligação sobre a pavimentação na comunidade Nações Indígenas, o que compartilhou conosco.

Fonte: Nascimento, 2019. - Foto: Fernanda Holanda.

De acordo com Ferreiro (2001 apud CANDAU, 2012, p. 114-115),

É preciso instrumentalizar didaticamente a escola para trabalhar com a diversidade. Nem a diversidade negada, nem a diversidade isolada, nem a diversidade simplesmente tolerada. Também não se trata da diversidade assumida como um mal necessário ou celebrada como um bem em si mesmo, sem assumir seu próprio dramatismo.

Nesse sentido, a diversidade é uma realidade presente nas escolas de todo o país, seja envolvendo raças, etnias, fronteiras, gêneros ou religiões. Independentemente de sua natureza, a diversidade deve ser assumida como um processo de transformação da sociedade contemporânea, que cada vez mais se torna multi e pluricultural nos mais diversos ambientes públicos ou privados, sendo matéria primordial para o trabalho das disciplinas curriculares, especialmente para o ensino de Ciências da Natureza. Por essa razão, ao finalizar a atividade, percebemos que há inúmeras possibilidades de promover um trabalho educativo de valorização das culturas, com vistas a caminharmos em direção a uma educação intercultural, pois, de acordo com Candau (2018, p. 223), nessa perspectiva podemos romper "com a visão essencialista das culturas e das identidades culturais [e] conceber as culturas em contínuo processo de elaboração, de construção e reconstrução". 
Para tanto, é preciso que haja predisposição e interesse em valorizar e promover as culturas presentes, convivendo no mesmo espaço e, no nosso caso, o espaço escolar. Entendemos que na situação da aula compartilhada realizada em nossa pesquisa promovemos essa valorização ao oportunizarmos a cada participante apresentar por meio de um mesmo conteúdo, porém com estratégias diferentes, seus valores morais, éticos, bem como suas vivências em contextos diversos, como um ensaio para educação na perspectiva intercultural nessa realidade em que convivem índios e não índios.

A ciência escolar, pela sua essência e por ser por excelência um tempo-espaço de diversidade, dado o caráter do conteúdo da disciplina, constitui-se em um canal por meio do qual podemos desencadear comportamentos que favoreçam a igualdade e a justiça curricular para os sujeitos. Desse modo, se pretendemos enfrentar esse grande desafio que nos propõe a Didática, precisamos transformar a diversidade em um instrumento de ação dessa transformação e reconhecê-la como vantagem pedagógica (CANDAU, 2012).

Portanto, a didática ou a prática na perspectiva da educação intercultural pode se constituir em um caminho pelo qual a escola pode trilhar, para diminuir a diferença entre os sujeitos culturais que fazem parte do currículo, ou pode ser uma alternativa didática, uma vez que vem sofrendo inúmeras revisões conceituais, sendo necessárias novas práticas e novas estratégias que facilitem o processo de ensino-aprendizagem e que partam de possibilidades apontadas pelos professores, conforme abordaremos no próximo tópico.

\section{EXPRESSÕES DE POSSIBILIDADES: O QUE PENSAM OS EDUCADORES}

Os professores que atuam nos anos iniciais têm a responsabilidade de boa parte da formação do sujeito-aluno, isto é, seu interesse pela escola, o gosto pela leitura, a preservação do meio ambiente e a valorização do que os demais colegas de sala trazem de suas raízes sociais e culturais. Diante dessa questão, pensarmos que as possibilidades das práticas exitosas podem surgir das experiências dos próprios professores, ao considerarmos suas vivências em sala de aula, pode ser a origem para iniciarmos novas perspectivas das necessidades formativas desses profissionais.

0 que estamos dizendo com isso é que, para realizarmos atividades que atendam às necessidades da sala de aula, não precisamos necessariamente trazer professores diferentes, mas, sim, possibilitar a esse professor atuante uma prática diferente e inclusiva, que abrace as culturas, respeite as diferenças e valorize a diversidade, para, dessa maneira, começar o processo educativo na perspectiva da educação intercultural pelo próprio professor, pois, na visão de Candau (2018, p. 225), é preciso "reconhecer positivamente as diferenças culturais e, ao mesmo tempo, promover processos que potencializem esta perspectiva". 
$\mathrm{Na}$ experiência da aula compartilhada realizada em nossa pesquisa, cujo foco foi o ensino de Ciências da Natureza, procuramos em cada momento ouvir os sujeitos envolvidos naquele processo e, ao final da ação, dispusemo-nos a ouvi-los novamente, com o propósito de buscarmos suas expressões acerca do que foi realizado e compartilhado na aula. Do que foi dito, destacamos algumas expressões que revelam a nobreza e relevância do trabalho realizado. Vejamos:

A professora regente da turma do primeiro ano expressou que:

Professora regente - É importante a interação; essa atividade poderia acontecer também no chapéu de palha do assentamento e fazer a relação com a língua deles, com foco na preservação dos animais, como a preservação dos humanos também; existem dificuldades para ensinarmos na escola, porque parece que eles [indígenas] não dão muita importância quanto à formação formal [escola/conteúdos], pois as atividades para casa retornam sem serem realizadas, mas ouvindo o que o cacique falou pude compreender um pouco melhor (NASCIMENTO, 2019, p. 167).

0 que podemos observar na fala da professora é que ela aponta que a interação entre as culturas é importante para melhorar a compreensão do modo de ser e de viver do outro. Mostra que há necessidade de interação entre as atividades da escola com o assentamento ou comunidade onde os indígenas moram, pois ela reconhece que com a presença do cacique na aula ela pôde compreender melhor algumas situações que têm influenciado o dia a dia da escola e o desempenho dos alunos indígenas. Assim como os alunos, o professor também necessita ser curioso para adquirir novas aprendizagens e, nesse sentido, Simone Selbach (2010, p. 30-31, grifo do autor) afirma que

Sem curiosidade não haverá investigação e sem investigação jamais se chegaria a Ciência. [...]. É por essa razão que um professor moderno deve buscar sempre fazer de seu aluno um caçador de curiosidades, estudante sempre capaz de "acender" nos alunos a curiosidade, ferramenta essencial de seu interesse pela aula e por sua vontade de transformação.

Referimo-nos a uma habilidade que deve ser intrínseca ao processo de ensino de Ciências da Natureza, a curiosidade para novas descobertas, sem a qual o professor não poderá elaborar questões e lançar dúvidas que desafiem os seus alunos para o ensino transformador de sua própria prática e da compreensão sobre esse componente curricular. Associar o conteúdo da sala de aula ao cotidiano do aluno pode ser uma estratégia que gera resultados

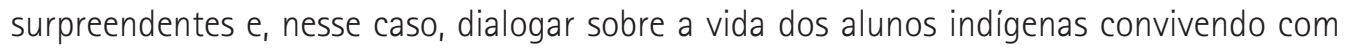
alunos não indígenas traz a possibilidade de aprendizagens significativas. 
Quanto ao cacique, não professor, mas elemento importante desse momento de compartilhamento, sentiu-se valorizado ao ser convidado para mostrar os seus saberes indígenas. Entretanto, durante a aula observamos que o cacique teve uma certa dificuldade na comunicação com as crianças, pois em determinados momentos não conseguiu adequar a sua linguagem ao nível de entendimento delas, precisando fazer um esforço na escolha das palavras para que elas compreendessem. Talvez isso tenha ocorrido pela falta de hábito de apresentar-se em uma atividade dessa natureza. Ao término de seu diálogo com os alunos, reportamo-nos ao cacique para ouvir suas considerações sobre a atividade, e esse expressou que: "não deveríamos perder a cultura do índio, pois o Brasil foi feito pelos indígenas e para não esquecerem quero repassar para as crianças, quero escrever um livro com a história dos animais, mesmo não sabendo ler" (NASCIMENTO, 2019, p. 168).

0 pensamento expresso pelo cacique demonstra que ele sente satisfação em estar presente em momentos como esses, para que a cultura indígena seja divulgada e não se torne desconhecida ou mesmo extinta nas próximas gerações, sejam elas indígenas ou não, e aponta para a importância do registro para que esse conhecimento não seja esquecido, para que se compreenda que existem diversas culturas e que essas podem se encontrar no interior da escola. Nesse sentido, Juan Olivencia (2016, p. 42, tradução nossa), assegura que

\footnotetext{
Na verdade, nossas escolas estão enfrentando o desafio da convivência intercultural. Não há dúvidas quando afirmamos que salas de aula e escolas passaram em pouco tempo de espaços monoculturais a espaços multiculturais com o intuito de construir cooperativamente uma educação intercultural que aprofunde a inclusão escolar.
}

Com efeito, nossas escolas, há muito tempo, já não são mais monoculturais, pois com as constantes imigrações de outros países, bem como de indígenas que deixam seus territórios, ambos os povos com o propósito de sobreviver, torna-se necessário nas escolas rever suas estratégias, visão de mundo e sua missão para a sociedade contemporânea que se apresenta diante dela, trazendo novos desafios no campo da diversidade e da inclusão social, racial, étnica e cultural.

Em relação à professora indígena, responsável pelo ensino de Cultura Indígena e da Língua Nheengatu, essa destacou que a experiência foi muito rica e que poderiam fazer isso mais vezes para que as crianças pudessem comparar a vida do índio nas aldeias e a vida fora dela. Ressaltou ainda que em uma próxima vez melhoraria o material, elaborando em tamanho maior e usaria o quebra-cabeça com as imagens dos animais também. Ela apontou que:

É importante o resgate da Língua, pois a identidade do índio não é o RANI e sim a Língua e, isto é para qualquer povo ou raça; quando se fala a Língua se identifica o sujeito e resgata o que foi perdido e em muitos lugares não há professor que ensine a Lingua, fundamental 
para cada povo, pois tem coisas que são específicas, só o índio faz, como por exemplo de onde vem a farinha de mandioca ou o uso do tapiri, o chapéu de palha que acolhe; é preciso desmistificar que o índio é preguiçoso (NASCIMENTO, 2019, p. 168-169).

A professora de Cultura Indígena nos aponta um fator fundamental nesse processo de educação na perspectiva intercultural: a língua, essencial para a propagação das culturas originais, para qualquer civilização, representa o elemento básico de identidade de um povo ou de uma cultura. Desde que os indios tiveram seus territórios invadidos, nas diversas regiões do Brasil, seus idiomas e dialetos originais foram desaparecendo e eles foram obrigados, para não perderem a comunicação, ou a aderir à lingua geral, conhecida como nheengatu ou aderir à língua portuguesa, dos colonizadores. Sobre essa questão, de grande relevância para a continuidade das culturas, Darcy Ribeiro (1996, p. 283) infere que vários grupos indígenas foram integrados após a invasão dos seus territórios e foram

Levados a viver juntos e diante da dificuldade de comunicação, por falarem línguas diversas, todos tiveram de adotar o português. Nessas circunstâncias, a geração mais nova, constituida em parte por filhos de casais mistos, nem chegou a aprender a língua dos pais. Desde sempre tribos indigenas vêm perdendo suas linguas pela adoção dos idiomas de grupos que as dominaram. Este fenômeno, que deveria ser raro nas condições originais de interação, parece ter se tornado mais frequente em virtude da interferência de núcleos civilizados.

É nesse contexto que entendemos que quando nos preparamos para adotar em nossas escolas uma educação na perspectiva da interculturalidade, especialmente no ensino de Ciências da Natureza, não precisamos necessariamente extinguir qualquer costume, valor ou mesmo a língua original dos povos vivendo na mesma comunidade. A máxima preservação dos traços de uma cultura em convivência com outras representa o respeito às diversas culturas e demonstra que não há hierarquias entre elas, que todas podem conviver e se entender, trocando saberes e conhecimentos, sem, contudo, anular a cultura do outro.

Portanto, as expressões oriundas da experiência vivida por esses atores e representantes culturais, em uma atividade de compartilhamento de saberes, apontaram como pontos relevantes que: 1. a interação entre as diversas culturas possibilita maior conhecimento do outro e de si mesmo e melhora a convivência humana; 2. a preservação das culturas, com o fim de propagá-las às próximas gerações, favorece a continuidade dos costumes de valores de uma civilização, sendo necessário, na atual conjuntura, o registro delas; 3. a língua é a principal identidade de um povo, pois, por meio dela, pode-se compreender os princípios de uma cultura, bem como o modo como os ancestrais se comunicavam durante a construção de sua história. Tais expressões podem se constituir em nortes ou pequenos rios para iniciarmos 
nossa viagem em direção a uma educação na perspectiva da interculturalidade, tomando como ponto de partida o ensino de Ciências da Natureza e seus conteúdos, os quais envolvem o cuidado e a preservação dos ambientes naturais, para a sobrevivência do homem, sendo ele mesmo parte integrante da natureza.

\section{CONSIDERAÇÕES FINAIS}

Significar as culturas dentro do contexto da diversidade nos parece um caminho possivel para alcançarmos a perspectiva de uma educação para a interculturalidade. Reconhecer os diferentes e tratá-los como iguais e considerar o outro um ser individual e coletivo na construção do ser cultural podem se constituir em uma saída para vencermos os preconceitos e as desigualdades que permeiam nossa sociedade - desigualdades que se concretizam no interior da escola, por meio de um currículo que exclui, segrega e fortalece a injustiça social. A diversidade cultural é fato no contexto contemporâneo de nossas escolas, sendo fundamental o sentimento de respeito no sentido de reconhecermos o outro em sua diferença, pois em determinado momento o "eu" se constitui no outro do outro. 0 respeito permite nos colocarmos no lugar do outro e buscarmos um diálogo democrático como garantia de direitos e como possibilidade de convivência humana pacífica para a promoção da justiça social e curricular.

Diante desse cenário de diversidade sociocultural, a formação do professor passa a ser tema fundamental de discussão e pesquisas científicas, uma vez que esse profissional representa um dos sujeitos com maior representatividade no desenvolvimento de estratégias para a construção de uma educação para a interculturalidade. Ao expandirmos nossa visão sobre a formação de professores para o ensino do aluno índio, expandimos também a oportunidade de incluir no currículo escolar novos sujeitos curriculares que já estão presentes na escola, mas que, no entanto, estão invisíveis para o currículo. Portanto, não se pode negar que essa é uma necessidade na realidade das escolas na contemporaneidade, em que se incluem alunos indigenas em escolas não indigenas. É necessário considerar para esses alunos a possibilidade de uma nova didática, com uma nova perspectiva para atender às necessidades de aprendizagem deles.

Acreditamos que a prática pedagógica e o trabalho do professor só são possíveis de serem realizados dentro do contexto cultural ao professar valores, compartilhar relações para a construção de conhecimentos, dando significação ao mundo e ao currículo. Ser professor é também um compromisso político-social, uma tomada de decisão do "como" e do "para que" ensinar, num desafio de situar a educação em um contexto político-social, para não se tornar um instrumento de manipulação; é trabalhar com as contradições; enxergar de uma perspectiva que considere as culturas e as interculturas existentes em cada contex- 
to real, na busca pela completude dos sujeitos curriculares e da melhoria das práticas em sala de aula.

Nesse sentido, as práticas desenvolvidas para o ensino de Ciências da Natureza para alunos indigenas inseridos em escolas não indigenas precisam conter um significado concreto, pois os indigenas concebem as Ciências da Natureza como algo concreto, visto que a natureza está presente em nosso dia a dia. Portanto, eles associam a disciplina à própria existência, uma vez que essa envolve a terra, a fauna, a flora, o cuidado com o meio ambiente, que são elementos fundamentais para que o homem também possa existir e subsistir. Ensinar Ciências da Natureza descontextualizada da realidade em que vivem os alunos, desconsiderando sua cultura, vivências, costumes e experiências, torna sem significado qualquer conteúdo ou atividade proposta. Há muito tempo já não temos mais, no Brasil, uma escola monocultural. As migrações, tanto da zona rural quanto de áreas indígenas, e a chegada de imigrantes criaram um cenário cultural em nossa sociedade e, consequentemente, as escolas que recebem os filhos desses "novos brasileiros" tornam as relações cada vez mais plurais.

\title{
Indigenous school education in non-indigenous school: sharing knowledge in a practice of teaching Sciences of Nature
}

\begin{abstract}
This article aims to socialize a practice in the teaching of Natural Sciences to indigenous students inserted in a non-indigenous school. The same is an excerpt from the field research of the PhD thesis Formação de professores e currículo: uma prática em Ciências da Natureza para a diversidade com alunos indígenas em escola não indigena na cidade de Manaus/AM (NASCIMENTO, 2019), in which the experience of a class shared between a conducting pedagogical teacher of a class of first year, a mura chief and an indigenous teacher of Indigenous Culture and Nheengatu Language. The shared class was the main technique used for data collection, whose purpose was to work on didactics from the perspective of interculturality. In the end, the collaborating subjects of the research presented several contributions that allowed us to establish a parameter on the importance of knowledge sharing. Our purpose in enabling such sharing of knowledge was na attempt to make indigenous culture visible among other cultures present at school that remain unnoticed. This reasoning allowed us to conduct a critical debate around the subject discussed in this work, since it is an approach to the valorization of cultural diversity within a multicultural context.
\end{abstract}

Keywords: Indigenous school education. Indigenous students. Non-indigenous school. Teaching of Natural Sciences. Shared lesson.

\section{REFERÊNCIAS}

CANDAU, V. M. Escola, didática e interculturalidade: desafios atuais. In: CANDAU, V. M. (org.). Didática crítica intercultural. Petrópolis: Vozes, 2012. p. 107-138. 
CANDAU, V. M. Interculturalidade no cotidiano escolar. In: CANDAU, V. M. (org.). Didática: tecendo/reinventando saberes e práticas. Rio de Janeiro: 7Letras, 2018. p. 220-235.

GRAÇA, T. S. M. R. da. A aprendizagem colaborativa no contexto do ensino-aprendizagem de português língua estrangeira. 2016. (Relatório de estágio em Humanidades) - Faculdade de Letras, Universidade do Porto, Porto, 2016.

MARINHO, E. Alunos vivenciam costumes, tradições e linguagens indigenas durante aula diferenciada. Manaus: Semed, 19 jul. 2017. Disponivel em: https://semed.manaus.am.gov.br/ alunos-vivenciam-costumes-tradicoes-e-linguagens-indigenas-durante-aula-diferenciada/. Acesso em: 5 jul. 2021.

NASCIMENTO, M. R. A. do. Educação intercultural e ensino de ciências: construção de conceitos em ciências naturais na escola indígena Baniwa e Coripaco - Pamáali, no Alto Rio Negro. 2010. Dissertação (Mestrado em Ensino de Ciências na Amazônia) - Universidade do Estado do Amazonas, Manaus, 2010.

NASCIMENTO, M. R. A. do. Formação de professores e currículo: uma prática em Ciências da Natureza para a diversidade com alunos indígenas em escola não indígena na cidade de Manaus/AM. 2019. Tese (Doutorado em Educação) - Pontificia Universidade Católica de São Paulo, São Paulo, 2019.

OLIVENCIA, J. J. L. Princípios pedagógicos de la educación para la convivencia intercultural. In: OLIVENCIA, J. J. L.; LÓPEZ, R. B. (coord.). Interculturalidad y escuela: perspectivas pedagógicas en la construcción comunitaria de la escuela intercultural. São Paulo: Cortez, 2016. p. 41-66.

RIBEIRO, D. Os índios e a civilização: a integração das populações indígenas no Brasil moderno. São Paulo: Companhia das Letras, 1996.

SANTIAGO, M. C.; AKKARI, A.; MARQUES, L. P. Educação intercultural: desafios e possibilidades. Petrópolis: Vozes, 2013.

SELBACH, S. Ciências e didática. Petrópolis: Vozes, 2010. (Coleção Como Bem Ensinar).

TORRES, P.; IRALA, E. Aprendizagem colaborativa: teoria e prática. In: TORRES, P. L. (org.). Complexidade: redes e conexões na produção do conhecimento. Curitiba: SENAR, 2014. p. 61-95. Disponivel em: https://www.agrinho.com.br/site/wp-content/uploads/2014/09/00_ Pretextuais_Livro_2.pdf. Acesso em: 5 jul. 2021. 